\title{
Disentangling What We Know About Microbes and Mental Health
}

\author{
Gregor Reid ${ }^{1,2 *}$ \\ ${ }^{1}$ Canadian R\&D Centre for Human Microbiome and Probiotics, Lawson Health Research Institute, London, ON, Canada, \\ 2 Department of Microbiology and Immunology, and Surgery, Western University, London, ON, Canada
}

OPEN ACCESS

Edited by:

John Bienenstock,

McMaster University, Canada

Reviewed by:

Bruno Bonaz,

Centre Hospitalier Universitaire de

Grenoble, France

Laurent Gautron,

University of Texas Southwestern

Medical Center, United States

*Correspondence:

Gregor Reid

gregor@uwo.ca

Specialty section:

This article was submitted to

Neuroendocrine Science,

a section of the journal

Frontiers in Endocrinology

Received: 10 July 2018

Accepted: 30 January 2019

Published: 15 February 2019

Citation:

Reid G (2019) Disentangling What We

Know About Microbes and Mental

Health. Front. Endocrinol. 10:81.

doi: 10.3389/fendo.2019.00081
Much has been written in recent years about the gut-brain axis. Exciting pilot studies suggest probiotic applications to the gut can reduce anxiety and depression via the vagus nerve. But not to diminish such findings, much still needs to be considered, including the fact that the vagus nerve links to many other body sites that also host a microbiome. Questions remain that touch the core of being human: (i) Do our microbes influence happiness and to what extent? (ii) What components of the gut microbiota and their function, including as it relates to mental health, are critical and how do they differ between agile, fit hunter gatherers and obese westerners or Danes described as the happiest people on the planet? (iii) What role do environmental pollutants play in this microbes-host ecosystem? While approaching life from a reductionist perspective has a long history in science, we need to try to interrogate these health and disease issues from a wider perspective. For verification of a link between the gut microbiota and brain, and to test new therapies, human studies are needed, and are long overdue.

Keywords: gut, Lactobacillus, probiotic, Hadza hunter-gatherers, brain

\section{INTRODUCTION}

There is arguably no better place to witness first-hand the impact that diet and microbes have on health and the way the brain functions, than in developing countries of Africa. The parasites and pathogens that can debilitate Westerners have long been known, and the resilience of the local Africans to many of these agents has played its part in the evolution of the hygiene hypothesis, understanding chronic diseases, and creation of a range of vaccines, including against the Ebola virus (1). Having been party to the study of Hadza hunter gatherers (2) and noting that they too can live to be elderly, it is clearly not a simple task to unmask the role of diet, microbes, and lifestyle in longevity.

It is challenging to dissect the effects of microbes on brain function. To date, the focus has been on pain, anxiety, depression (3), centered in the amygdala within the limbic system, and linked through the vagus nerve. These studies have not examined the more positive emotions of happiness, drive, and contentment that often appear to be in high abundance among Africans, despite their often-dire predicament.

This paper will explore the potential interplay between food, microbes and lifestyle, and challenge researchers to verify rodent research in humans. 


\section{TRYING TO UNDERSTAND THE MICROBIOTA THROUGH RETRACING HUMAN EVOLUTION}

While the environments of Canada and east Africa certainly differ to a large extent, as do diets for the majority of citizens, there are also commonalities. For example, the vaginal microbiota shares the same dominant Lactobacillus strains across continents, likely indicating their contribution to successful reproduction (4).

In search of increasing our understanding of microbiome evolution, studies have been performed on ancient hunter gatherers in Africa and South America. While they are not free from influence by modern society, some of the habits remain intact. A recent study showed that the Hadza gut microbiota is influenced by seasonal dietary intake, varying from meat to certain fruits (2). The resultant increase in diversity is likely a hallmark of how humans used to consume food, except that Westernized societies have access to clean water, unlike the Hadza who live in the Central Rift Valley in Tanzania, have significant hand-fecal (human and animal) exposure, and drink untreated water. Indeed, the introduction of un-milled maize to individuals normally consuming baobab, roots, berries, and honey significantly changed their gut microbiota (5).

But, how such seasonality and microbial patterns influence mood has not been studied. The ability to cover great distances in bare feet, hunting animals, securing a temporary home, and providing for women and offspring cannot only be a measure of testosterone and $\mathrm{Y}$ chromosomes. If that were the case, the same drive would arguably be present in Hadza hunter gatherers who have assimilated into the lifestyles of Westernized Africans, consuming processed foods, using pharmaceutical agents, and receiving vaccines. Indeed, testosterone levels in one group of Hadza were found not to change with age, and not to be linked to total energy expenditure (6). The loss of Treponema sp. and acquisition of Bifidobacterium sp. has been reported in Westernized hunter gatherers, the Treponema being more suitable for degradation of unrefined plants, and the bifidobacteria better suited to utilizing gluco- and galacto-based saccharides of Western foods (7). So, diet and lifestyle do alter the microbiota, but this does not prove a correlation with changes in energy and happiness.

Norway, Denmark, and Sweden are ranked in the category of happiest places to live (8), based upon governance, personal freedom, opportunity, education, safety, and healthcare. Suicide rates are around 11 per 100,000 , yet approximately half Norwegians will suffer depression at some point in their life (9). Are rates of depression a more suitable measure of happiness and contentment, and if so, what about depression amongst hunter gatherers? Based on observations from Papua New Guinea reporting no depression in hunter gatherers, an explanation was consumption of omega- 3 fatty acids, access to regular sunlight, exercise, social interaction, and healthier sleep (10). So, could a supplement of certain probiotic strains, vitamin $\mathrm{D}$, and omega-3 fatty acids reduce depression rates in countries where people have good access to employment, housing, education, and healthcare? These are questions that require investigation.

\section{THE GAP BETWEEN MOUSE STUDIES AND HUMANS}

Much has been made of the link between autism and the gut microbiota (11). One study using a mouse model suggested that Bacteroides fragilis therapy had potential to resolve behavioral symptoms in autistic humans (12). Whether an already unnatural mouse develops autism does not then translate into a therapeutic breakthrough for autistic children, particularly when analytical flaws in the study were exposed by others (13). Such studies lead to internet blogs that distort the reality and raise hope for a cure in parents. Although scientists have little control over how lay people or the media represent their work, the way that conclusions are presented and the rigor of the review process to minimize sensationalizing results have a major impact.

The basis of too many microbiome studies, to date, has been rodent experiments, or observational studies in humans, neither of which prove cause and effect. In the case at hand, parents desperate to help their autistic child might look to fecal microbiota transplant or a $B$. fragilis probiotic that does not exist and will take many years to develop, believing these treatments will alleviate certain behaviors. It is not for me to say that such interventions will or will not work, but there should be a better scientific basis for suggesting they might be effective. Instead, the senior author of the mouse paper (12) published a review in the same journal Cell (14) reiterating the link between the gut microbiota and the brain including autism spectrum disorder as if it was proven in humans, when almost all the citations refer to mouse experiments, and human observations. Indeed, the review itself cites numerous other reviews making the same points based on rodent experiments.

The possibility that vast numbers of microbes in the intestinal tract with the potential to produce compounds that include neurochemicals $(15,16)$ can influence the brain is compelling. That the vagus nerve is a main conduit for such signaling (17) is suggested by the vastness of innervation and sensory fibers, and by vagotomy studies (18), but other sites especially in the urogenital and respiratory tracts served by this nerve also have microbiotas (19). Indeed, afferent nerves within the vagus innervate almost all visceral organs, and in the airways and lungs, vagal sensory neurons are the major afferent supply and close to $20 \%$ terminate there $(20)$. The airway microbiota contains a number of species quite capable of influencing the nervous system $(21,22)$. These discoveries have led to the concept of a gut-lung axis, influenced by diet and the microbiota $(23,24)$. The importance of the vagus nerve in the microbe-gut-brain axis (25) has led to exploration of chronically stimulating the nerve to treat Crohn's disease (26). However, vagus nerve stimulation therapy is not without difficulty, and requires a wire with three helical contacts and a one-pin battery, which can potentially lead to infections, delayed arrhythmias, hoarseness, dyspnea, coughing, and vocal cord damage emphasizing the linkage between the nerve and sites other than the gut (27). In studies of the gut-brain 
access via the vagus nerve, it may prove challenging to deduce the extent to which organisms in the gut vs. other sites linked to the nerve, are impacting the brain. Of note, the contribution of the vagus nerve to monitoring the microbiome is based on marginal evidence apart from a few vagotomy studies, and such animals suffer from impaired gastrointestinal functions. In addition to the vagus nerve, the intestinal mucosa has sensory functions and neurons, endocrine cells, and immune cells which act as detectors (28). This makes it possible for the brain to control important functions such as gut motility.

What has so far been lacking is identification of molecules produced by microbes that are responsible for brain effects. Arguably, the tools are available to identify these in humans through use of various metabolomic and proteomic methods, and access through surgical procedures. Descriptions of what could, and indeed should, be done in humans, has been lacking from the multitude of reviews on the gut-brain axis, with one exception. Hooks et al. (29) recently raised similar salient points as those made here, including the relevance of rodent studies to humans (30), and calling for research that deciphers the complexity of the multipathway systems. Notably, they state "It could be well-worth working with relevant public health and media experts on how to communicate this exciting body of work responsibly" [(29), page 27]. They also add to the discussion the potentially important role of environmental factors in brain related illness, an issue that will be discussed below. The impact of microbial metabolites on the brain is unclear. Only a few $G$ protein-coupled transmembrane molecular sensors have been identified metabolites in the $\mathrm{Na}_{\mathrm{v}} 1.8$-expressing vagal afferents that detect neurotransmitters, hormones, nutrients (31).

Certainly, omics tools could be applied now to patients with multiple sclerosis and other brain related illnesses who are receiving fecal microbiota transplants (FMT) (32) or are taking a variety of probiotics, thereby supporting or rebuking the theories based on rodents. Such research could also be applied to verify other mouse-based studies, for example that suggest FMT from a lean donor can make an obese recipient lose weight (33). Eleven years after this widely cited study, no such conclusive human verification has occurred.

The translation of in vitro and animal studies to human experimentation has at least started to occur, with encouraging results against depression by daily ingestion of probiotic bifidobacteria for 6 weeks (34). The selection of the Bifidobacterium longum NCC3001 subspecies longum strain was from mouse studies 6 years prior showing that ingestion normalized anxiety-like behavior and hippocampal brain derived neurotrophic factor (BDNF) levels (35). The study utilized a range of evaluative tools. Functional MRI analysis showed that reduced responses to negative emotional stimuli in multiple brain areas, including amygdala and fronto-limbic regions, occurred with probiotic treatment compared to placebo. The lack of change in serum inflammatory markers suggested the benefit did not accrue through down-regulation of inflammation. The unchanged levels of neurotrophins and neurotransmitters 5-HT, substance P, and CGRP, would suggest that gut bacteria were not increasing the circulatory levels of at least these three neurotransmitters, even though reductions were noted in urinary levels of phenylacetyglutamine, creatine, 4-cresol sulfate, and trimethylamine-N-oxide. It was no surprise that the fecal microbiota was unchanged, as $16 \mathrm{~s}$ rRNA Illumina sequencing is not sensitive enough to detect differences and probiotic strains do not necessarily alter microbial abundances. As to how the probiotic strain was mediating the clinical outcome the answer remains to be found but given the success of this study of 44 subjects, additional trials are warranted, perhaps accompanied by metagenomic, or transcriptomic analyses to see if the bifidobacteria were influencing other microbes or host circuitry.

A challenge for researchers wanting to use microbes to prevent autism spectrum disorder is that interventions will likely need to be tested while the fetus is developing and during early life. This will ethically be more difficult as microbiota manipulation through FMT, probiotics or prebiotics tends not to be target specific, so how the intervention affects other developmental processes will be of concern. On the other hand, if these gut-brain and microbiome-host linkages are true, then the development of every human is already being influenced by a series of microorganisms and in-depth studies during pregnancy and the first year after birth could help to reveal some of the processes. For example, a probiotic strain that improves gut barrier integrity and therefore helps increase adsorption of arachidonic acid, docosahexaenoic acid, and omega-3 polyunsaturated fatty acids, critical for brain growth and cognitive development, could well be tested $(36,37)$, with implications for later-in-life (38).

As it stands, there are similarities between the challenges facing the microbiome area, still in its infancy, and methodological issues in the field of nutritional epidemiology (39). The author, Ioannidis, viewed most nutritional variables could be correlated with one another if large enough data sets were analyzed. Confounding factors add to the complexity and meta-analyses become weighted averages interpreted by the examiners. As with foods that can contain thousands of chemicals with the most abundant assumed to be responsible for harm or health, so too assumptions are made that abundant microbial taxa are the key influencer. Probing low abundance species and ruling out contamination remain challenges in microbiome studies. As noted above, the propensity of journals to increase manuscript Altmetric scores does not mean the paper or its conclusions represent meaningful results. Ioannidis' call for exploration of new avenues of research and pivotal human trials should drive granting agencies to redirect funds away from often pointless or non-correlative animal experiments.

\section{PROBIOTICS}

As eluded to by Hooks et al. (29), the field of probiotics which faced cynicism in the earlier days of its reemergence (40), is yet again being slated for its lack of usefulness. Unfortunately, the number of people who not understand what probiotics are, and what they are not, is reflected in these commentaries. 
This is illustrated by a commentary on the Hsiao et al. paper (12) that referred to the $B$. fragilis strain as a probiotic (41), which until proven to confer a health benefit on the host, it is not a probiotic (42). One recent poorly designed and analyzed paper stated in its title a link between small intestinal bacterial overgrowth, probiotics, and metabolic acidosis (43), when no such correlation was found (44). An Israeli group published studies with a product they referred to as "probiotic" but that had failed to meet the well-documented criteria as a probiotic [it did not show a health benefit: (45)]. They tested it in only a handful of healthy subjects and claimed the strains did not colonize and therefore could not be effective $(46,47)$, even though colonization is not a prerequisite for probiotic strains. In addition, they claimed that probiotics in general might cause harm if used to prevent antibiotic-associated diarrhea, even when no harm was shown. A much more thorough study of almost 400 subjects in a double-blind design, showed that a multi-strain probiotic could in fact correct undesired changes in microbiota composition and function, caused by antibiotic treatments or by cesarean birth (48). This adds to the meta-analysis data showing the benefits of probiotics to prevent antibiotic-associated diarrhea (49).

As Hooks et al. noted, too many microbiome studies, of which the two recent ones are examples $(46,47)$, "oversell" their limited findings, and in doing so damage a reputable scientific field of probiotics. Such overselling is not exclusive to microbiome research, and of course it can be found across the scientific literature, including for some probiotic studies. But, the point of importance is that such negativity should not lead to cessation of good investigative studies on the potential for microbial interventions to provide a benefit to human mental health.

In addition to the example highlighted above (34), several other excellent studies have shown that probiotic therapy can improve mental health. In a New Zealand study of 423 women, Lactobacillus rhamnosus HN001 taken during pregnancy and post-partum significantly reduced depression and anxiety scores compared to placebo (50). In a study investigating neurocognitive impairment in $10 \mathrm{HIV}-1$ infected patients, 6 months intake of a product containing Lactobacillus plantarum DSM 24730, Streptococcus thermophilus DSM 24731, Bifidobacterium breve DSM 24732, Lactobacillus paracasei DSM 24733, Lactobacillus delbrueckii subsp. bulgaricus DSM 24734, Lactobacillus acidophilus DSM 24735, Bifidobacterium longum DSM 24736, and Bifidobacterium infantis DSM 24737 showed significant improvements in Rey auditory verbal learning test (immediate and delayed recall), Rey-Osterrieth complex figure test (copy immediate and delayed recall), phonological verbal fluency test, Toronto alexithymia scale-20, State-trait anxiety inventory Y-2, and time and weight estimation test scores (51). Interestingly, while one strain of $B$. longum was shown in a small study to improve memory and reduce stress (52), another paired with $L$. helveticus showed no effect on psychological outcome measure (Cohen's d range $=0.07-0.16$ ) (53). Although study designs and subject characteristics differed, it is worth investigating strain to strain variations.

\section{ENVIRONMENTAL AND SOCIO-ECONOMIC CONFOUNDERS}

As has been well-documented, mental health, and well-being are affected by a number of factors, not the least of which are socio-economic status and environmental pollutants. Such confounders must be considered in human studies if we are to truly differentiate the role of microbes in alleviating depression, anxiety, and improving treatment of conditions emanating from the brain. Whether this is lack of exposure to coastal waters (54), unemployment (55), being in a household where illness, and death are prevalent (56) or being exposed to small pollutant particles penetrating the blood brain barrier (57), these can influence depression. One study has even suggested that exposure to air pollutants in early life can alter the gut microbiome and increase the risk of various diseases (58). A number of pesticides have been clearly shown to induce neurological disease (59). In some developing countries, sexually transmitted infections and excessive blood or hair mercury levels can be a result of poverty and women trading sex for fish from polluted lakes (60).

In every clinical study, efforts are made to match confounding issues in the active and placebo arms, but perhaps not to the extent of measuring levels of heavy metals and pesticides. These are not only issues for developing countries, but certainly the contamination risk appears to be higher. In a study performed in Mwanza, Tanzania, probiotic L. rhamnosus GR1 yogurt intake correlated with reduced adsorption of mercury, and arsenic in pregnant women consuming contaminated fish from Lake Victoria (61). The lactobacilli were shown to bind to the metals. The subsequent creation of a network of 282 production units across east Africa that make probiotic yogurt made with the GR-1 or L. rhamnosus GG generic strain Yoba known also strengthen gut barrier function (62), has the potential to not only reduce toxin uptake and improve nutrient adsorption, but also indirectly improve mental health and well-being. By increasing family income for the producers and along the value chain, the resultant lifestyle, and socio-economic changes could impact rates of depression and anxiety.

This whole-view of society is vital if diseases are to be effectively treated. Unless women are empowered, children are fed, income allows for education and healthcare, and crop losses are minimized, then disease more easily proliferates. A single vaccine or pharmaceutical agent can undoubtedly save lives, but the cost to society in waiting for them to be developed, tested, implemented, and paid for is invariably long; and by the time the shareholders reap the benefits from the consumers directly or countries donating funds for product use, many lives could have been saved or improved in developing countries by simpler remedies borne out of local empowerment. This is not to imply that a probiotic can cure Ebola or malaria, but a practical, affordable probiotic food could indeed be as effective in improving health and well-being, as a capsule imported from the North at a price many-fold higher. 


\section{CONCLUDING REMARKS}

Health is not a single event. Rather, it is a continuum along which peaks and troughs occur, some more dramatic than others. Microbes are present throughout, and it will be generations before we know how best to program their functionality to impart health and wellness for as long as possible. But, we need scientific rigor in conjunction with translational speed and regulatory flexibility. It need not be driven by large multinationals.

The Hadza have managed without central heating, air conditioning, sugary soda, and automobiles. Some of them live to be very old. Many of them seem happier than the Western scientists who visit them. While fellow humans change the environment in which they live, it may be wise for us to first understand not only the microbes that live in and on the Hadza and the species that surround them, but also how the complexities of human cells, microbes, chemicals, food, and the ecosystem intermingle.

Research into the microbiome has to extend beyond rodent models, as recently shown by a study of over one thousand subjects that identified microbial metabolites correlating with mental quality of life and depression (63). Cancer has been

\section{REFERENCES}

1. Henao-Restrepo AM, Longini IM, Egger M, Dean NE, Edmunds WJ, Camacho A, et al. Efficacy and effectiveness of an rVSV-vectored vaccine expressing Ebola surface glycoprotein: interim results from the Guinea ring vaccination cluster-randomised trial. Lancet (2015) 386:857-66. doi: 10.1016/S0140-6736(15)61117-5

2. Smits SA, Leach J, Sonnenburg ED, Gonzalez CG, Lichtman JS, Reid G, et al. Seasonal cycling in the gut microbiome of the Hadza hunter-gatherers of Tanzania. Science (2017) 357:802-6. doi: 10.1126/science.aan4834

3. Rea K, O'Mahony SM, Dinan TG, Cryan JF. The role of the gastrointestinal microbiota in visceral pain. Handb Exp Pharmacol. (2017) 239:269-87. doi: 10.1007/164_2016_115

4. Reid G. Cervicovaginal microbiomes - threats and possibilities. Trends Endocrinol Metabol. (2016) 27:446-54. doi: 10.1016/j.tem.2016.04.004

5. Fragiadakis GK, Smits SA, Sonnenburg ED, Van Treuren W, Reid G, Knight R, et al. Links between environment, diet, and the hunter-gatherer microbiome. Gut Microbes. (2018) 17:1-12. doi: 10.1080/19490976.2018.1494103

6. Pontzer H, Raichlen DA, Wood BM, Emery Thompson M, Racette SB, Mabulla AZ, et al. Energy expenditure and activity among Hadza huntergatherers. Am J Hum Biol. (2015) 27:628-37. doi: 10.1002/ajhb.22711

7. Soverini M, Rampelli S, Turroni S, Schnorr SL, Quercia S, Castagnetti A, et al. Variations in the post-weaning human gut metagenome profile as result of Bifidobacterium acquisition in the western microbiome. Front Microbiol. (2016) 7:1058. doi: 10.3389/fmicb.2016.01058

8. https://www.forbes.com/pictures/mef45jgim/4-australia/\#a8141056647e

9. http://www.newsinenglish.no/2009/10/06/depression-hits-half-thepopulation/

10. https://bottomlineinc.com/health/depression/hunter-gatherer-curedepression

11. Roman P, Rueda-Ruzafa L, Cardona D, Cortes-Rodríguez A. Gut-brain axis in the executive function of autism spectrum disorder. Behav Pharmacol. (2018) 29:654-63. doi: 10.1097/FBP.0000000000000428

12. Hsiao EY, McBride SW, Hsien S, Sharon G, Hyde ER, McCue T, et al. Microbiota modulate behavioral and physiological abnormalities associated with neurodevelopmental disorders. Cell. (2013) 155:1451-63. doi: 10.1016/j.cell.2013.11.024 cured many times over in rodents without necessarily doing the same in humans, and clear concerns about animal models and microbiota studies translating to humans have been expressed (64-67). In addition to studies not taking account of the influence of coprophagy (68), many experimental tools and models used to manipulate the microbiome of laboratory rodents are inherently flawed, including the use of antibiotics which have neuro-active and neuro-toxic effects and therefore can influence gut-brain outcomes (69). Concepts can be tested in humans through FMT, probiotics, prebiotics, and dietary alterations. Access to tissue and real-time responses is more feasible now with non-invasive surgery. Such studies will help to clarify conflicting data (70) and make it possible to develop novel approaches to treatment of humans suffering from a range of brain-associated illnesses. Surely, the 17 years it apparently takes to translate science into something that makes a difference to human life (71) is not set in stone?

\section{AUTHOR CONTRIBUTIONS}

The author confirms being the sole contributor of this work and has approved it for publication.

13. Gloor GB, Reid G. Compositional analysis: a valid approach to analyze microbiome high throughput sequencing data. Can J Microbiol. (2016) 62:692-703. doi: 10.1139/cjm-2015-0821

14. Sharon G, Sampson TR, Geschwind DH, Mazmanian SK. The central nervous system and the gut microbiome. Cell (2016) 167:915-32. doi: 10.1016/j.cell.2016.10.027

15. Iyer LM, Aravind L, Coon SL, Klein DC, Koonin EV. Evolution of cell-cell signaling in animals: did late horizontal gene transfer from bacteria have a role? Trends Genet (2004 20:292-9. doi: 10.1016/j.tig.2004.05.007

16. Lyte M. Probiotics function mechanistically as delivery vehicles for neuroactive compounds: microbial endocrinology in the design and use of probiotics. Bioessays (2011) 33:574-81. doi: 10.1002/bies.2011 00024

17. Forsythe P, Bienenstock J, Kunze WA. Vagal pathways for microbiomebrain-gut axis communication. Adv Exp Med Biol. (2014) 817:115-33. doi: 10.1007/978-1-4939-0897-4_5

18. Perez-Burgos A, Wang B, Mao YK, Mistry B, McVey Neufeld KA, Bienenstock J, et al. Psychoactive bacteria Lactobacillus rhamnosus (JB-1) elicits rapid frequency facilitation in vagal afferents. Am J Physiol Gastrointest Liver Physiol. (2013) 304:G211-20. doi: 10.1152/ajpgi.00128.2012

19. Reid G, Burton JP. Making sense of urinary microbiota data for clinical urology. Nature Rev Urol. (2016) 13:567-8. doi: 10.1038/nrurol.2016.182

20. Mazzone SB, Undem BJ. Afferent innervation of the airways in health and disease. Physiol Rev. (2016) 96:975-1024. doi: 10.1152/physrev.00039. 2015

21. Hilty M, Burke C, Pedro H, Cardenas P, Bush A, Bossley C, et al. Disordered microbial communities in asthmatic airways. PLoS ONE (2010) 5:e8578. doi: 10.1371/journal.pone.0008578

22. Zakharkina T, Heinzel E, Koczulla RA, Greulich T, Rentz K, Pauling JK, et al. Analysis of the airway microbiota of healthy individuals and patients with chronic obstructive pulmonary disease by T-RFLP and clone sequencing. PLoS ONE (2013) 8:e68302. doi: 10.1371/journal.pone.0068302

23. Dumas A, Bernard L, Poquet Y, Lugo-Villarino G, Neyrolles O. The role of the lung microbiota and the gut-lung axis in respiratory infectious diseases. Cell Microbiol. (2018) 17:e12966. doi: 10.1111/cmi.12966

24. Anand S, Mande SS. Diet, microbiota and gut-lung connection. Front Microbiol. (2018) 9:2147. doi: 10.3389/fmicb.2018.02147 
25. Bonaz B, Bazin T, Pellissier S. The vagus nerve at the interface of the microbiota-gut-brain axis. Front Neurosci. (2018) 12:49. doi: 10.3389/fnins.2018.00049

26. Bonaz B, Sinniger V, Hoffmann D, Clarençon D, Mathieu N, Dantzer C, et al. Chronic vagus nerve stimulation in Crohn's disease: a 6-month follow-up pilot study. Neurogastroenterol Motil. (2016) 28:948-53. doi: 10.1111/nmo. 12792

27. Giordano F, Zicca A, Barba C, Guerrini R, Genitori L. Vagus nerve stimulation: surgical technique of implantation and revision and related morbidity. Epilepsia (2017) 58 (Suppl. 1):85-90. doi: 10.1111/epi.13678

28. Furness JB, Kunze WA, Clerc N. Nutrient tasting and signaling mechanisms in the gut II The intestine as a sensory organ: neural, endocrine, and immune responses. Am J Physiol. (1999) 277:G922-8.

29. Hooks KB, Konsman JP, O'Malley MA. Microbiota-gut-brain research: a critical analysis. Behav Brain Sci. (2018) 12:1-40. doi: 10.1017/S0140525X18002133

30. Nguyen TLA, Vieira-Silva S, Liston A, Raes J. How informative is the mouse for human gut microbiota research? Dis Models Mech. (2015) 8:1-16. doi: $10.1242 / \mathrm{dmm} .017400$

31. Egerod KL, Petersen N, Timshel PN, Rekling JC, Wang Y, Liu Q, et al. Profiling of $\mathrm{G}$ protein-coupled receptors in vagal afferents reveals novel gut-to-brain sensing mechanisms. Mol Metab. (2018) 12:62-75. doi: 10.1016/j.molmet.2018.03.016

32. Borody TJ, Leis S, Campbell J, Torres M, Nowak A. Fecal microbiota transplantation (FMT) in multiple sclerosis (MS). Am Coll Gastroenterol. (2011) 106:S352.

33. Turnbaugh PJ, Bäckhed F, Fulton L, Gordon JI. Diet-induced obesity is linked to marked but reversible alterations in the mouse distal gut microbiome. Cell Host Microbe. (2008) 3:213-23. doi: 10.1016/j.chom.2008.02.015

34. Pinto-Sanchez MI, Hall GB, Ghajar K, Nardelli A, Bolino C, Lau JT, et al. Probiotic Bifidobacterium longum NCC3001 reduces depression scores and alters brain activity: a pilot study in patients with irritable bowel syndrome. Gastroenterology (2017) 153:448-59.e8. doi: 10.1053/j.gastro.2017.05.003

35. Bercik P, Park AJ, Sinclair D, Khoshdel A, Lu J, Huang X, et al. The anxiolytic effect of Bifidobacterium longum NCC3001 involves vagal pathways for gut-brain communication. Neurogastroenterol Motil. (2011) 23:1132-9. doi: 10.1111/j.1365-2982.2011.01796.x

36. Rombaldi Bernardi J, de Souza Escobar R, Ferreira CF, Pelufo Silveira P. Fetal and neonatal levels of omega-3: effects on neurodevelopment, nutrition, and growth. Sci World J. (2012) 2012:202473. doi: 10.1100/2012/ 202473

37. Del Piano M, Anderloni A, Balzarini M, Ballarè M, Carmagnola S, Montino F, et al. The innovative potential of Lactobacillus rhamnosus LR06, Lactobacillus pentosus LPS01, Lactobacillus plantarum LP01, and Lactobacillus delbrueckii subsp. delbrueckii LDD01 to restore the "gastric barrier effect" in patients chronically treated with PPI: a pilot study. J Clin Gastroenterol. (2012) 46 (Suppl.):S18-26. doi: 10.1097/MCG.0b013e318267b55d

38. Kovacs GG, Adle-Biassette H, Milenkovic I, Cipriani S, van Scheppingen J, Aronica E. Linking pathways in the developing and aging brain with neurodegeneration. Neuroscience (2014) 269:152-72. doi: 10.1016/j.neuroscience.2014.03.045

39. Ioannidis JPA. The challenge of reforming nutritional epidemiologic research. JAMA (2018) 320:969-70. doi: 10.1001/jama.2018.11025

40. Atlas RM. Probiotics - snake oil for the new millennium? Environ Microbiol. (1999) 1:377-82. doi: 10.1046/j.1462-2920.1999.00063.x

41. Gilbert JA, Krajmalnik-Brown R, Porazinska DL, Weiss SJ, Knight R. Toward effective probiotics for autism and other neurodevelopmental disorders. Cell (2013) 155:1446-8. doi: 10.1016/j.cell.2013.11.035

42. FAO/WHO. Guidelines for the Evaluation of Probiotics in Food (2002). Available online at: http://www.fao.org/food/food-safety-quality/a-z-index/ probiotics/en/

43. Rao SSC, Rehman A, Yu S, Andino NM. Brain fogginess, gas and bloating: a link between SIBO, probiotics and metabolic acidosis. Clin Transl Gastroenterol. (2018) 9:162. doi: 10.1038/s41424-0180030-7

44. Quigley EMM, Pot B, Sanders, ME. "Brain Fogginess" and D-lactic acidosis: probiotics are not the cause. Clin Transl Gastroenterol. (2018) 9:187. doi: 10.1038/s41424-018-0057-9
45. Hod K, Sperber AD, Ron Y, Boaz M, Dickman R, Berliner S, et al. A doubleblind, placebo-controlled study to assess the effect of a probiotic mixture on symptoms and inflammatory markers in women with diarrhea-predominant IBS. Neurogastroenterol Motil. (2017) 29:e13037. doi: 10.1111/nmo.13037

46. Suez J, Zmora N, Zilberman-Schapira G, Mor U, Dori-Bachash M, Bashiardes $\mathrm{S}$, et al. Post-antibiotic gut mucosal microbiome reconstitution is impaired by probiotics and improved by autologous FMT. Cell. (2018) 174:1406-23.e16. doi: 10.1016/j.cell.2018.08.047

47. Zmora N, Zilberman-Schapira G, Suez J, Mor U, Dori-Bachash M, Bashiardes $\mathrm{S}$, et al. Personalized gut mucosal colonization resistance to empiric probiotics is associated with unique host and microbiome features. Cell. (2018) 174:1388-1405.e21. doi: 10.1016/j.cell.2018.08.041

48. Korpela K, Salonen A, Vepsäläinen O, Suomalainen M, Kolmeder C, Varjosalo $\mathrm{M}$, et al. Probiotic supplementation restores normal microbiota composition and function in antibiotic-treated and in caesarean-born infants. Microbiome (2018) 6:182. doi: 10.1186/s40168-018-0567-4

49. Cruchet S, Furnes R, Maruy A, Hebel E, Palacios J, Medina F, et al. The use of probiotics in pediatric gastroenterology: a review of the literature and recommendations by Latin-American experts. Paediatr Drugs (2015) 17:199-216. doi: 10.1007/s40272-015-0124-6

50. Slykerman RF, Hood F, Wickens K, Thompson JMD, Barthow C, Murphy R, et al. Effect of Lactobacillus rhamnosus HN001 in pregnancy on postpartum symptoms of depression and anxiety: a randomised double-blind placebo-controlled trial. EBio Med. (2017) 24:159-65. doi: 10.1016/j.ebiom.2017.09.013

51. Ceccarelli G, Fratino M, Selvaggi C, Giustini N, Serafino S, Schietroma I, et al. A pilot study on the effects of probiotic supplementation on neuropsychological performance and microRNA-29a-c levels in antiretroviral-treated HIV-1-infected patients. Brain Behav. (2017) 7:e00756. doi: 10.1002/brb3.756

52. Allen AP, Hutch W, Borre YE, Kennedy PJ, Temko A, Boylan G, et al. Bifidobacterium longum 1714 as a translational psychobiotic: modulation of stress, electrophysiology and neurocognition in healthy volunteers. Transl Psychiatry (2016) 6:e939. doi: 10.1038/tp.2016.191

53. Romijn AR, Rucklidge JJ, Kuijer RG, Frampton, C. A double-blind, randomized, placebo-controlled trial of Lactobacillus helveticus and Bifidobacterium longum for the symptoms of depression. Aust $N Z J$ Psychiatry (2017) 51:810-21. doi: 10.1177/0004867416686694

54. Dempsey S, Devine MT, Gillespie T, Lyons S, Nolan, A. Coastal blue space and depression in older adults. Health Place (2018) 54:110-7. doi: 10.1016/j.healthplace.2018.09.002

55. Bijlsma MJ, Tarkiainen L, Myrskylä M, Martikainen P. Unemployment and subsequent depression: a mediation analysis using the parametric G-formula. Soc Sci Med. (2017) 194:142-150. doi: 10.1016/j.socscimed.2017.10.011

56. Burger R, Posel D, von Fintel M. The relationship between negative household events and depressive symptoms: evidence from South African longitudinal data. J Affect Disord. (2017) 218:170-5. doi: 10.1016/j.jad.2017.04.031

57. Gładka A, Rymaszewska J, Zatoński T. Impact of air pollution on depression and suicide. Int J Occup Med Environ Health (2018) 31:711-21. doi: 10.13075/ijomeh.1896.01277

58. Vallès Y, Francino MP. Air pollution, early life microbiome, and development. Curr Environ Health Rep. (2018) 5:512-21. doi: 10.1007/s40572-0180215-y

59. Cassereau J, Ferré M, Chevrollier A, Codron P, Verny C, Homedan C, et al. Neurotoxicity of Insecticides. Curr Med Chem. (2017) 24:2988-3001. doi: 10.2174/0929867324666170526122654

60. Sileo KM, Kintu M, Kiene SM. The intersection of intimate partner violence and HIV risk among women engaging in transactional sex in Ugandan fishing villages. AIDS Care (2018) 30: 444-52. doi: 10.1080/09540121.2017. 1391985

61. Bisanz JE, Enos MK, Mwanga JR, Changalucha J, Burton JP, Gloor GB, et al. Randomized open-label pilot study of the influence of probiotics and the gut microbiome on toxic metal levels in Tanzanian pregnant women and school children. MBio (2014) 5:e01580-14. doi: 10.1128/mBio.01580-14

62. Orlando A, Linsalata M, Notarnicola M, Tutino V, Russo F. Lactobacillus GG restoration of the gliadin induced epithelial barrier disruption: the role of cellular polyamines. BMC Microbiol. (2014) 14:19. doi: $10.1186 / 1471-2180-14-19$ 
63. Valles-Colomer M, Falony G, Darzi Y, Tigchelaar EF, Wang J, Tito RY, et al. The neuroactive potential of the human gut microbiota in quality of life and depression. Nat Microbiol. (2019). doi: 10.1038/s41564-0180337-x

64. Hackam DG, Redelmeier, DA. Translation of research evidence from animals to humans. JAMA (2006) 296:1731-2. doi: 10.1001/jama.296. 14.1731

65. Perel P, Roberts I, Sena E, Wheble P, Briscoe C, Sandercock P, et al. Comparison of treatment effects between animal experiments and clinical trials: systematic review. BMJ (2007) 334:197. doi: $10.1136 / \mathrm{bmj}$. 39048.407928.BE

66. Mak IW, Evaniew N, Ghert M. Lost in translation: animal models and clinical trials in cancer treatment. Am J Transl Res. (2014) 6:114-8.

67. Franklin CL, Ericsson AC. Microbiota and reproducibility of rodent models. Lab Anim. (2017) 46:114-22. doi: 10.1038/laban.1222

68. Ebino KY. Studies on coprophagy in experimental animals. Jikken Dobutsu. (1993) 42:1-9. doi: 10.1538/expanim1978.42.1_1

69. Champagne-Jorgensen K, Kunze WA, Forsythe P, Bienenstock J, McVey Neufeld KA. Antibiotics and the nervous system: more than just the microbes? Brain Behav Immun. (2018). doi: 10.1016/j.bbi.2018.12.014. [Epub ahead of print].

70. Eisenstein M. Microbiome: bacterial broadband. Nature (2016) 533:S104-6. doi: $10.1038 / 533 S 104 a$

71. Morris ZS, Wooding S, Grant J. The answer is 17 years, what is the question: understanding time lags in translational research. $J$ R Soc Med. (2011) 104:510-20. doi: 10.1258 /jrsm.2011.110180

Conflict of Interest Statement: GR has consulted on the topic of probiotics for Seed, Acerus Pharma, KGK Synergize, Bayer Consumer Health, Chr Hansen, Metagenics, and Standard Process in the past three years. He receives no licensing fees from the sale of probiotics and has no stock ownership or patents on the topic.

Copyright $\odot 2019$ Reid. This is an open-access article distributed under the terms of the Creative Commons Attribution License (CC BY). The use, distribution or reproduction in other forums is permitted, provided the original author(s) and the copyright owner(s) are credited and that the original publication in this journal is cited, in accordance with accepted academic practice. No use, distribution or reproduction is permitted which does not comply with these terms. 